\title{
Variations in basic demographics consequential to population size of governorate in Saudi Arabia
}

\author{
Rshood Khraif ${ }^{1}$, Asharaf Abdul Salam", Rajaram Subramanian Potty ${ }^{2}$, Ali Aldosari ${ }^{1}$, Ibrahim Elsegaey ${ }^{1}$ \\ and Abdullah AlMutairi ${ }^{1}$
}

\begin{abstract}
Saudi Arabia, divided into 5 planning regions, 13 administrative regions and further to 118 governorates (administrative units), has diverse demographic characteristics from one region to another and from one governorate to another. Rural to urban migration and an exodus of immigrants characterize the Kingdom, where development planning depend largely upon local level requirements based on economic activities. An attempt was made to analyze the population characteristics, such as population size, sex ratio, native to foreigner ratio, and households and persons per households by keeping governorate as unit of analysis. Data of two census period (2004 and 2010) was used in order to explore the situation and track the intercensal changes. Large variations in population were observed between governorates and it varied from 3686 to 5,007,886 in 2010. Governorates are divided according to the number of native population demarcating urbanization, modernization and infrastructure. During the intercensal period, the number of small governorates reduced and medium and large sized governorates increased mainly due to population growth. The average population in governorates was increased in total and in the larger governorates during the period. However, we noticed a reduction in the average population size in the small and medium sized governorates. The size of native population in a governorate influences the sex ratio, the native-foreigner ratio and the persons per household as well as the variations within the group of governorates. Analyses of lower level data shall aid not only to understand the situation but also to support local development policies.
\end{abstract}

Keywords: Coefficient of variation, Administrative units, Population ratios, Immigration, Native versus foreign population

\section{Background}

There has been a change in all dimensions of demography including population growth, immigration, urbanization, age distribution and labor force participation in Saudi Arabia, which is the largest country in the Arabian Peninsula (Alrouh et al. 2013). These changes lead to modifications in the socio-economic conditions and infrastructure-housing, education and health. The population growth is the result of the natural increase, traditional Islamic culture (Wincker 1997) and labor oriented immigrations (Khraif 2000, 2007) along the improvement

\footnotetext{
*Correspondence: asalam@ksu.edu.sa

${ }^{1}$ Center for Population Studies, King Saud University, Riyadh, Saudi Arabia Full list of author information is available at the end of the article
}

in living conditions, quality of life and infrastructure resulting from economic prospects and urbanization (Susilawati and Al-Surf 2011).

Demographically, Saudi Arabia encourages pronatalist policies that create high fertility despite the prevailing low mortality (Freedman 1995; Jacobson 1994; Omran and Roudi-Fahimi 1993). However, birth rates declined as a result of educational improvements and increasing age at marriage in the Kingdom (Al-Mazrou et al. 1995; Al-Nasser and Bamgboye 1992). The Kingdom has 7.4 \% of 359 million Arabs-65.1 \% of the Gulf Cooperation Council-GCC (Alrouh et al. 2013; Center for Population Studies 2013; Rashad 2000). The undergoing fertility transition (Alrouh et al. 2013; Khraif 2009; Courbage 1999) of the Kingdom can be attributed to the improvement 
in health status (United Nations 2002; Shawky 2001). But the existing youth bulge and immigration of foreign laborers (Collemore 2003; Samman 1985); unbalanced sex ratio (Parasuraman 2002); regional disparities in physical and social infrastructure (Al-Khalifeh 1993); increased demands for education, housing, health care and employment (Roudi-Fahimi 1993); and residential mobility (Khraif 1994) in the rapidly urbanizing Saudi Arabia (Susilawati and Al-Surf 2011; Sly and Serow 1993) receive attention of both reformers and policy makers. More than three-fifths of the population of Saudi Arabia lives in major cities, where networks of transportation as well as most basic services are well organized and integrated.

The alarmingly urbanizing Kingdom of Saudi Arabia (Khraif 2007) has relatively integrated transportation networks and most basic services (UNDP 2004) addressing the increasing demand for public services such as piped water, electricity, sewage, telephone (United Nations 2006; Makki 1986), housing and transportation (AlGabbani 2008) even though with wide spread disparities in physical and social infrastructure (Al-Khalifeh 1993) observed across administrative areas. Local level variations visibly based upon not only the geographic characteristics but also the developmental paradigms are noted. Saudi Arabia has an East West Corridor of development (Khraif 2007) connecting Eastern Region, Al-Riyadh, AlMadina Al-Monawarah and Makkah Al-Mokarramah, having residential, commercial, and industrial and port networks. This population concentrated corridor has the Kingdom's majority of developmental activities-education, health, road, and housing infrastructure-demanding both national and foreign labor force. Other regions, on the north and the south, having low population density comprising of lesser commercial and industrial activities; thus having less demand for labor force.

Within the regions, governorates differ widely in terms of population size including national and expatriate, and infrastructure-education, health and other utilities. It is the population size in a given region that determines other factors reflecting demographic, social, economic, and health conditions. Demographic indicators such as sex ratio, native-expatriate ratio and persons per household has significance not only in the changing migration and labor laws in the Kingdom but also in the regional development and population redistribution efforts. It is in this context, an analysis of governorates of the Kingdom of Saudi Arabia is carried out using 2004 and 2010 census data.

\section{Data and methodology}

The present paper provides comparable and most recent data on changes on the current characteristics of the population in Saudi Arabia by regions and groups of governorates according to their population size. The census data (published by the Ministry of Economics and Planning) for the years 2004 and 2010 was analyzed in detail using MSExcel and SPSS (version 20), and applied suitable statistical methods. Governorates were classified into three such as small ( $<50,000$ population), medium $(50,000-100,000)$ and large $(100,000+)$, according to the size of Saudi population, have been analyzed keeping governorate as the unit of quantifying Saudi and nonSaudi population; sex ratio; Saudi-non-Saudi ratio; and average number of persons per household. In addition, we also calculated the coefficient of variation to find out the difference in the population parameters between various governorates as per the classification of Saudi population. Caution is required while interpreting the totals in comparison with the categories based on Saudi population, across the census years, as the denominator (number of governorates) differs, due to the use of preliminary and final census (2010).

\section{Results and discussions}

Data analyses have been made in this paper to explore population size, sex ratio, native-foreigner ratio, number of households and persons per household.

\section{Population of governorates}

Governorates, the administrative units, in Saudi Arabia have not been formed according to the population size but to the local level development requirements. In total, there are 118 governorates from the thirteen regions of the country (see Table 1). The number of governorates are highest in the Al-Riyadh region (20) followed by Jazan (14), Makkah Al-Mokarramah (12), Aseer (12), $\mathrm{Al}$-Qaseem (11) and Eastern Region (11). The number of governorates is least in Al-Jouf (3), Northern Borders (3) and Hail (4). According to the census 2004, 62 governorates (52.5\%) in Saudi Arabia, have less than 50,000 native population; 24 governorates $(20.4 \%)$ have native population of size between 50,000 and 100,000 and the remaining 32 governorates ( $27.1 \%$ ) have 100,000 or more native population. The number of governorates with the same native population size was changed to 50 (42.4\%), $32(27.1 \%)$ and $36(30.5 \%)$ in the year 2010 . Thus there is a reduction of 10 percentage point in the number of small governorates between the two census periods. Consequently, the number of medium and large governorates increased by about 7 and 3 percentage points, respectively. These governorates have both urban and rural areas with increasing inhabitation in small towns and medium sized cities having investments in urban development (United Nations 2006; UNDP 2004; Sly and Serow 1993) leading to huge expansion and rapid growth of cities in the Kingdom (Khraif 1994). In the year 2004, 
Table 1 Distribution of governorates by Saudi population size, across regions

\begin{tabular}{|c|c|c|c|c|c|c|c|}
\hline \multirow[t]{2}{*}{ Region } & \multicolumn{3}{|l|}{2004} & \multicolumn{3}{|l|}{2010} & \multirow[t]{2}{*}{ Total } \\
\hline & $<50,000$ & $50,000-100,000$ & $100,000+$ & $<50,000$ & $50,000-100,000$ & $100,000+$ & \\
\hline Al-Riyadh & $11(55.0)$ & $6(30.0)$ & $3(15.0)$ & $11(55.0)$ & $4(20.0)$ & $5(25.0)$ & $20(100.0)$ \\
\hline Makkah Al-Mokarramah & $6(50.0)$ & $1(8.3)$ & $5(41.7)$ & $5(41.7)$ & $2(16.7)$ & $5(41.7)$ & $12(100.0)$ \\
\hline Al-Madina Al-Monawarah & $4(57.1)$ & $1(14.3)$ & $2(28.6)$ & $1(14.3)$ & $4(57.1)$ & $2(28.6)$ & $7(100.0)$ \\
\hline Al-Qaseem & $8(72.7)$ & $1(9.1)$ & $2(18.2)$ & $8(72.7)$ & - & $3(27.3)$ & $11(100.0)$ \\
\hline Eastern Region & $5(45.5)$ & - & $6(54.5)$ & $4(36.4)$ & $1(9.1)$ & $6(54.5)$ & $11(100.0)$ \\
\hline Aseer & $3(25.0)$ & $5(41.7)$ & $4(33.3)$ & $1(8.3)$ & $6(50.0)$ & $5(41.7)$ & $12(100.0)$ \\
\hline Tabouk & $5(83.3)$ & - & $1(16.7)$ & $4(66.7)$ & $1(16.7)$ & $1(16.7)$ & $6(100.0)$ \\
\hline Hail & $2(50.0)$ & $1(25.0)$ & $1(25.0)$ & $2(50.0)$ & $1(25.0)$ & $1(25.0)$ & $4(100.0)$ \\
\hline Northern Borders & $1(33.3)$ & $1(33.3)$ & $1(33.3)$ & $1(33.3)$ & $1(33.3)$ & $1(33.3)$ & $3(100.0)$ \\
\hline Jazan & $8(57.1)$ & $2(14.3)$ & $4(28.6)$ & $3(21.4)$ & $7(50.0)$ & $4(28.6)$ & $14(100.0)$ \\
\hline Najran & $6(75.0)$ & $1(12.5)$ & $1(12.5)$ & $6(75.0)$ & $1(12.5)$ & $1(12.5)$ & $8(100.0)$ \\
\hline Al-Baha & $3(42.9)$ & $4(57.1)$ & - & $3(42.9)$ & $4(57.1)$ & - & $7(100.0)$ \\
\hline Al-Jouf & $1(33.3)$ & - & $2(66.7)$ & $1(33.3)$ & - & $2(66.7)$ & $3(100.0)$ \\
\hline Total & $62(52.5)$ & $24(20.3)$ & $32(27.1)$ & $50(42.4)$ & $32(27.1)$ & $36(30.5)$ & $118(100.0)$ \\
\hline
\end{tabular}

no governorate was identified as medium size in the Eastern Region, Tabouk and Al-Jouf. However, in the year 2010, the regions of Al-Qaseem and Al-Jouf did not have any medium sized governorate. Similarly, none of the governorates in Al-Baha region had native population of 100,000 or more in the year 2004 and 2010.

Thus, the increase in population per governorate reflects the increase in population during the intercensal period, due mainly to the natural increases. Governorates grouped according to the number of native population, shows an increasing trend of governorates by population. This, on the other hand indicates local level developments, urban growth, and expansion of small and medium sized governorates, during the intercensal period 2004-2010.

In the year 2010 (Final Results), total population of 26.1 million persons lived in 4,652,162 housing units in Saudi Arabia. Out of the total population, 19.3 million are native persons (74.1\%) lived in 2,996,253 housing units (the preliminary results shows a total population of 27.1 million, out of which 18.7 million are Saudi-68.9 \%living in 4.6 million housing units). Comparatively, as per the census 2004, the total population was about 22.7 million, lived in 3,991,783 housing units. The count of native population was about 16.5 million (72.9\%) lived in $2,761,738$ housing units. The remaining $27.1 \%$ in the year 2004 and $25.9 \%$ in the year 2010 were foreigners, mostly from South Asian and African countries.

It shows an alarming increase of expatriate population in the Kingdom during the intercensal period of 2004-2010. Consequently, the significant proportion of expatriate population, characteristic of GCC nations, exerts pressure on social and economic life leading to unemployment of natives as well as shortage of basic supplies (Khraif 2009; Collemore 2003). Such an influx of foreign labor has developed from the scenario of a small number of national population employed in public sector that attracts foreign labor in other sectors of infrastructure development-power stations, government ministries and services, and industrial and agricultural units (Wincker 1997), though the situation undergoing rapid changes recently. The population in Saudi Arabia was grown by 2.5 persons annually during the period 2004-2010. However, during the same period the native population was grown by 2.8 persons annually. Thus, establishes the population growth from 2004 to 2010 affecting housing units, native to foreigner population, and the labor force composition; consequently, influencing the national demographic scenario.

\section{Population size}

We calculated the average population size in the governorates and the results are provided in the Table 2 . Overall, in the year 2010, the governorates in the Kingdom had a population size of 221,106 persons per governorate, on an average (163,859 native and 57,247 non-native), and the average population size in 2004 was 192,189 persons per governorates (140,062 native and 52,126 non-native). While the small governorates had a mean population of 35,839 and 34,196; medium governorates had 76,818 and 74,265 and large governorates had 581,645 and 611,226 in the year 2004 and 2010, respectively. The result thus indicates that the population growth during the inter-census period was mainly at the large governorates. In each class 


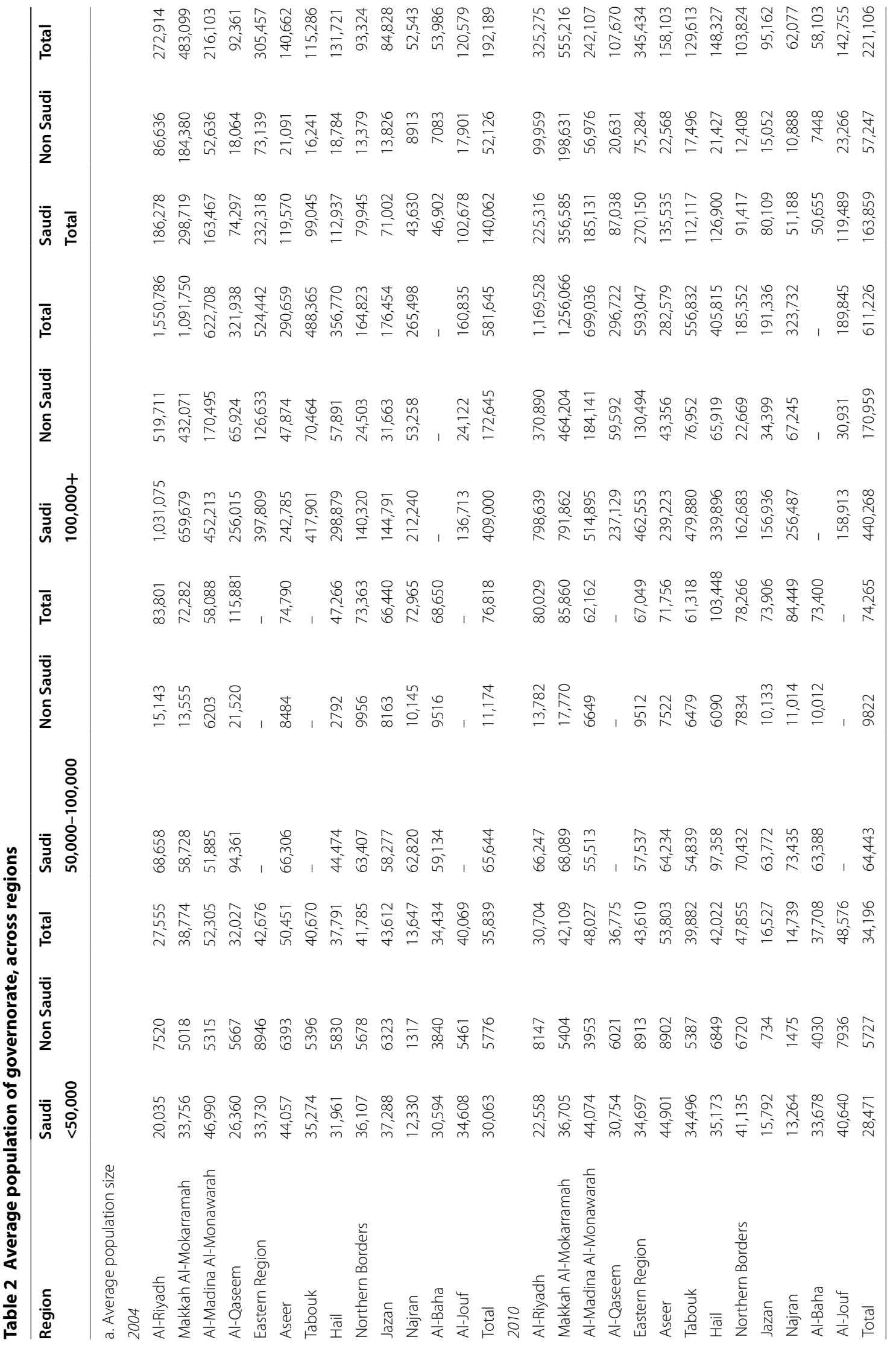


of governorates, the population size of non-native persons is proportional to population size of native persons. For example, in both study years large governorates had higher number of non-native persons. In other words, a higher number of native persons in a governorate boost the size of non-native persons.

This trend-native to expatriate widened during the intercensal period, despite concerted efforts in line with nationalization of labor force. Such changes during the intercensal period are of concern to the demographers and other policy oriented researchers as the increasing trend of expatriates in the Kingdom shall have long term implications on population distribution and family formations.

Overall, both in 2004 and 2010 , the average population of the native persons per governorate was highest in Makkah Al-Mokarramah, followed by Al-Riyadh and Eastern Region. However, in 2004 Najran, Al-Baha, and Jazan had lowest mean population of the native persons per governorate. In 2010, lowest average population of native persons per governorate was in Al-Baha followed by Najran and Jazan. As per the 2004 census, the average population size of native persons in the small governorates was lowest in the Najran region followed by Al-Riyadh, Al-Qaseem, Al-Baha and Hail. In case of medium governorates, the average population size of native persons was lowest in the region $\mathrm{Al}$-Madina $\mathrm{Al}$ Monawarah followed by Jazan, Makkah Al-Mokarramah and Al-Baha. On the other hand, Al-Riyadh and Makkah Al-Mokarramah had the highest average native persons in the governorates classified as large. Mass migrations from rural to urban areas increasing over urbanization, alarm the growth of primate city (Makki 1986)-Riyadh, which is the fastest growing city in the Middle East (Susilawati and Al-Surf 2011), where a large number of non-native persons are brought for employment (Center for Population Studies 2013).

Population size in these governorates has increased markedly during the intercensal period, in line with population growth of the Kingdom, in general. It is the medium and large governorates whose population expanded remarkably in the period. It shows the governmental efforts in line with development in both medium and large governorates, neglecting the smaller ones.

\section{Sex ratio}

Sex ratio as provided by the census was examined and it was found that the over all sex ratio was 132 in 2010 but 124 in 2004 (Table 3), showing an increasing trend. It ranged from 118 to 134 in different governorates classified according to their population size of native persons in 2010, whereas it ranged between 112 and 126 in 2004; again an increasing trend. While we identified a balanced sex ratio of 104 males per 100 females among the native persons in 2010 it ranged from 98 to 106 in governorates as per their population size of native persons. However, in 2010 an imbalanced sex ratio of 238 males per 100 females was identified for non-native persons and the highest sex ratio among the non-native persons was in the small governorates. This higher sex ratios of the expatriates is alarming indicating the male dominating labor sector in the Kingdom and its requirements, especially in the smaller governorates. In the medium and larger governorates, labor force demands more technical and professional expatriates accommodating families.

In 2004, the sex ratio among non-native was also high at 227 males per 100 females and ranged from 216 to 384 in various governorates grouped as per the population size of native persons. Here too a widening sex ratio trend observed showing the increased requirements at domestic level, low skilled expatriate labor. That is, over the time, the tendency to employ low skilled and unskilled expatriates laborers increasing leading to demographic imbalances reflecting in the sex ratio. This might be an outcome of nationalization movement reducing skilled and professional expatriates.

It is important to note that sex ratio among the nonnative persons declines with increasing number of native persons in a governorate. This may be due to the fact that small governorates bring expatriates in single-non family-status whereas larger governorates bring expatriates with family status; again depend upon the manpower requirements. Rapid urbanization (Telvizian 2009; Khraif 2007; United Nations 2006; Khraif 1994; Makki 1986) and influx of foreign labor (Collemore 2003; Khraif 2009; Wincker 1997; Alghamdi 1995) disturbs the sex ratio, depending upon the labor requirements; thus "Saudi Arabia and the nearby Qatar and Kuwait have the highest sex ratios in the world" (Parasuraman 2002). But the sex ratios are changing among the native Saudi community, as a result of environmental effects on reproductive health (Babay 2004), which is debatable. The increase in the overall sex ratio between 2004 and 2010 was mainly due to the larger increase in the sex ratio among nonnative persons (11 percentage points) as compared to native person ( 3 percentage points). This widening sex ratio trend receives attention requiring caution at policy levels.

While the sex ratio changes among native persons is due to environmental effects; that of non-native persons is attributed to the labor importation (immigration) policies. Over all, the sex ratio was increased in all the regions between 2004 and 2010 with the highest increment in $\mathrm{Al}$-Jouf region. This increase attributed to the trend followed by the non-native persons. But, sex ratio of nonnative persons was declined in Al-Qaseem (26 points), 


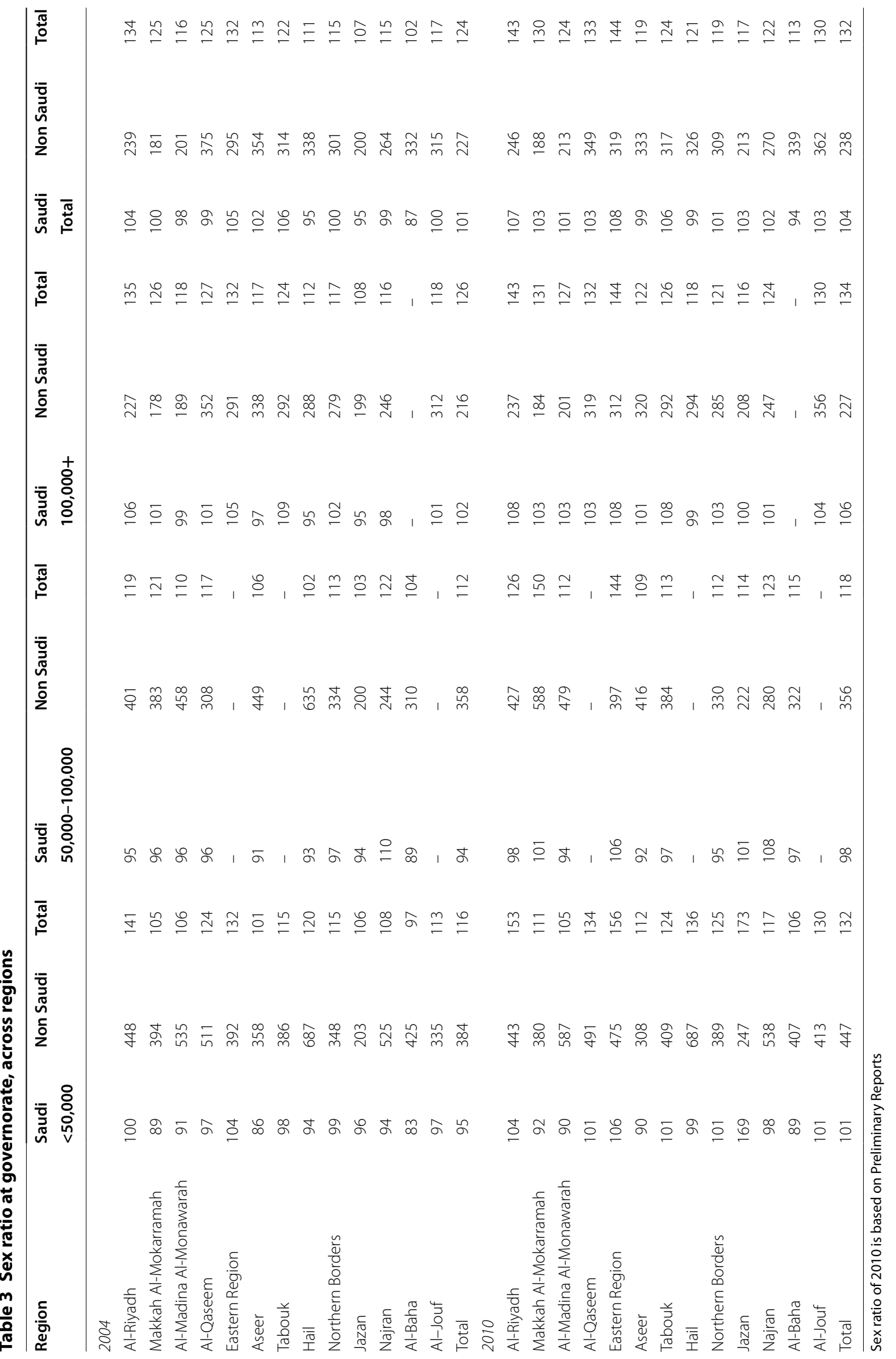


Aseer (21 points) and Hail (12 points) regions between 2004 and 2010. Among the smaller governorates, Aseer region had experienced the highest decline in the sex ratio among the non-native persons between 2004 and 2010, followed by Al-Qaseem, Al-Baha, Makkah AlMokarramah and Al-Riyadh. However, in other regions of the small governorate group, we noticed an increase in the sex ratio among the non-native persons with maximum sex ratio change of 83 percentage points in Eastern Region and 78 percentage points in the $\mathrm{Al}$-Jouf region. In the small governorates, we noticed a higher increase in the sex ratio among native persons in the Jazan region. Thus, the trend of sex ratio varies depending on the livelihood options and development activities regionally. The increasing infrastructure development during the intercensal period might have caused this trend.

In the medium governorate regions, a slight decline in the sex ratio among native persons was observed in three regions such as Al-Madina Al-Monawarah, Northern Borders, and Najran between 2004 and 2010 and the sex ratio was increased in other regions of the country during the same period. Among the non-native persons the sex ratio declined in the medium governorates in the regions of Aseer and Northen Borders. Highest increment in sex ratio among non-native persons in medium governorates was in Makkah Al-Mokarramah region, attributed to higher requirements of male labor force to serve the pilgrim population. In the large governorates, the difference in the sex ratio between 2004 and 2010 among the native persons was found to be small. Whereas, in case of non-native persons sex ratio was declined in the large governorates of $\mathrm{Al}$-Qaseem and Aseer regions and it was increased in other regions. Increasing sex ratio cautions the policy making processes for its significance in reproductive health. On, the other hand, sex ratio of nonnative persons remains high showing the gender specific labor oriented migration (Center for Population Studies 2012) to fulfill the labor requirements for efficient development programs. Thus, it is of a theoretical concern and a status issue, while including the labor immigrants in the sex ratio frame work.

\section{Ratio of population}

An issue of concern to the fast developing Kingdom of Saudi Arabia is the exodus of expatriates hailing from Asia as well as Africa (Khraif 2009; Collemore 2003; Wincker 1997). There are 349 non-native per 1000 native population in the Kingdom (making 259 per 1000 persons), as of 2010 showing a decreasing trend compared to 2004 (372 out of Saudi and 271 out of total). Such a fast decreasing ratio indicates the changing labor markets and infrastructural development in the Kingdom (Table 4). In both 2004 and 2010, the ratio of non-native population to native population was small in medium governorates compared to small and large governorates. An overall ratio of 741:259 (native: non-native) observed in the Kingdom at governorate level, in 2010; the corresponding ratio during 2004 was 729:271 indicating a declining trend in the non-native population. The results indicate that population of non-natives decreased more in the medium and large governorates between 2004 and 2010. This gives hope for the efforts of nationalization movement in line with improving employment of national population.

The ratio of population in the regions for various governorates with different native population size shows lower non-native to native population was found in the governorates of Northern Borders followed by Al-Baha and Tabouk regions, whereas highest ratio was noticed in the regions of Makkah Al-Mokarramah and Al-Riyadh, in the year 2010 (Table 4). Governorates in regions with less urban population and urban infrastructure have lesser ratio; those urbanized regions have higher ratio: thus reflecting upon the demand for foreign laborers in those region's developmental activities and life styles. Between 2004 and 2010, the non-native to native population ratio declined tremendously in Makkah Al-Mokarramah (60 points) followed by Eastern Region (36 points), Northern Borders (31 points) and Al-Riyadh (21 points). However, the ratio of non-native to native population was found to have increased during the period in governorates of few regions, such as Al-Jouf, Najran and Hail. This trend is crucial especially in the context of increasing number of expatriates in proportion with the native population. On the other hand, it shows the effect of nationalization strategy implementation.

In 2010, among the smaller governorates group, AlRiyadh region followed by the Eastern Region had the highest ratio of non-native to native population and Jazan region had the lowest ratio. Between 2004 and 2010, in the small governorates, Jazan region had the largest decline in the non-native population followed by Al-Madina Al-Monawarah. But, governorates in Aseer, Al-Jouf and Hail region's ratio of non-native to native population has increased during the period. In the medium governorates Makkah Al-Mokarramah and Al-Riyadh regions had the highest ratio of non-native population in 2010 . We noticed an increase in the ratio of non-native to native population in two regions of medium governorates, namely Makkah Al-Mokarramah and Jazan between 2004 and 2010. In the larger governorates Makkah Al-Mokarramah and Al-Riyadh regions had the highest ratio of non-native to native population in 2010. There was an increase in the non-native population in larger governorates of Al-Jouf and Najran during the period 2004-2010. 


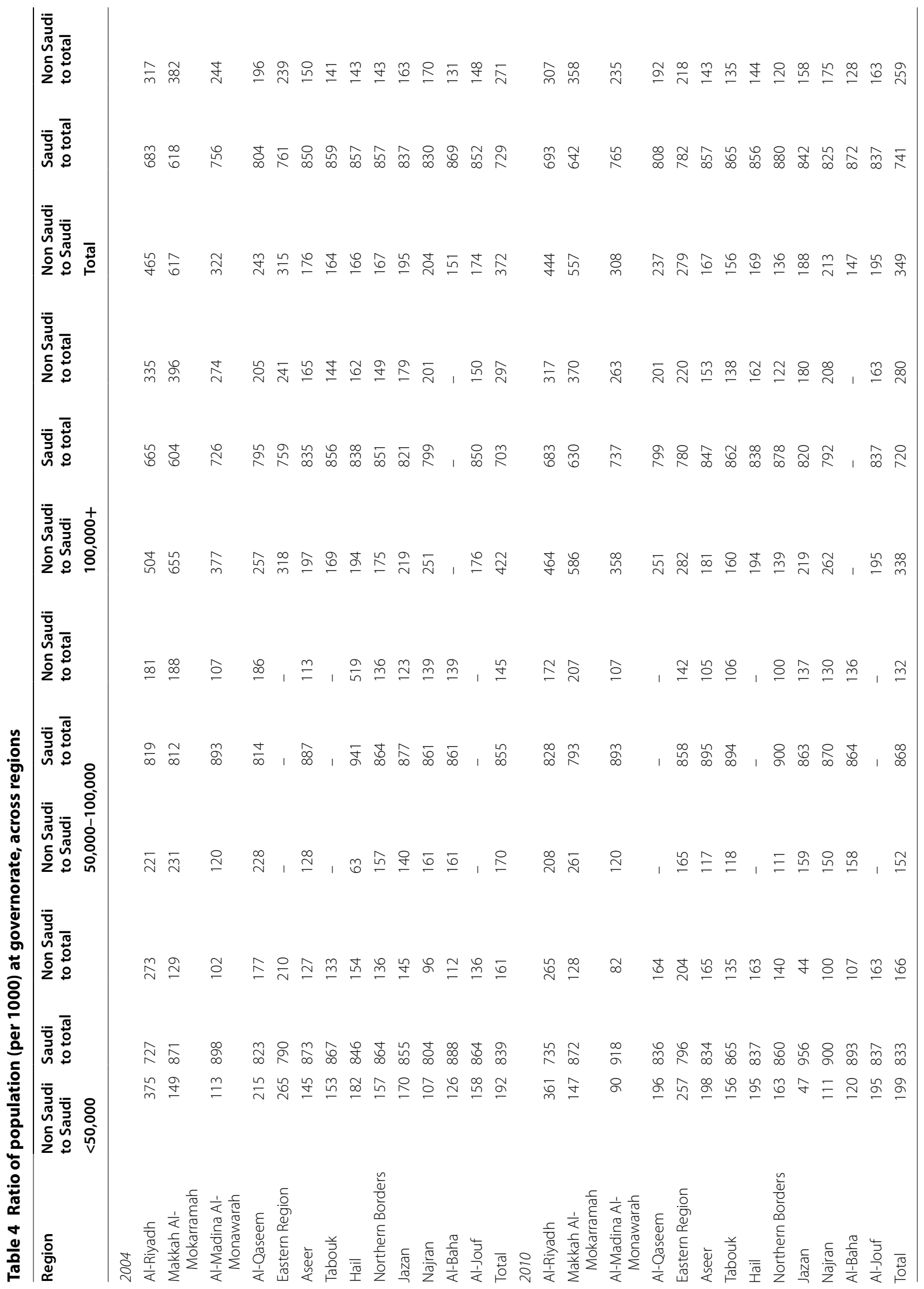




\section{Households}

In 2010, on an average there was 39,450 households per governorate in the Kingdom (4,655,127 in total); out of them $25,417(2,999,218$ in total) belonging to native person whereas $14,033(1,655,909$ in total) belonging to nonnative person. The corresponding number of households in the year 2004 was $33,890(3,999,011$ in total), 23,466 $(2,768,966)$ and $10,424(1,230,045)$, respectively; suggesting an increasing trend over the period. This increase might be proportional to the population combined with the effect of nucleation of families. In all types of governorates, the native population had the highest number of households, which also agrees with the population size.

Apparently smaller governorates included lesser number of average households belonging to both native and non-native persons. Overall, in 2004 the average size ranged between 2361 and 9288 households in the smaller governorates (1870-7487 in case of native persons and 491-2157 in case of non-native persons). On the other hand, medium sized governorates included 13,123 households, on an average and ranged between 9318 and 18,707 (7804-12,015 in case of native persons and 12994231 in case of non-native persons). The average number of households in the larger governorates was 103,360 and it ranged between 21,666 and 271,628.

In total, the mean number of households per governorates varied from 10,679 (Najran) to 110,743 (Makkah Al-Mokarramah), as of 2010 and the mean for 2004 was 8742 (Najran) and 98,159 (Makkah Al-Mokarramah). The results also suggests that governorates in Al-Riyadh and Eastern Region had comparatively higher number of households and governorates whereas Al-Baha, Northern Borders, Jazan and Al-Qaseem had comparatively lesser number of households (Table 5). Among the small governorates Aseer and Al-Jouf regions had the highest average number of households in 2010. However, in 2004 AlMadina Al-Monawarah and Aseer regions found to have the highest average number of households. In 2010, minimum number of average households in the small governorates was identified in Jazan and Najran, and in 2004 the same was observed in Najran and Al-Riyadh regions. Similarly, in 2010 Makkah Al-Mokarramah, Hail and AlRiyadh regions had the high mean number of households among the medium size governorates, whereas Eastern Region, Jazan and Tabouk regions had governorates with low mean number of households. However, in 2004 AlQaseem, Makkah Al-Mokarramah and Al-Riyadh regions had the maximum mean number of households and Jazan and Northern Borders regions are found to have the minimum average number of households in a governorate. In both 2010 and 2004, larger governorates in the regions of Makkah Al-Mokarramah and Al-Riyadh had highest mean number of households. In 2010, lowest mean number of households was found in the governorates of Northern Borders and Jazan regions and in 2004 it was minimum in the governorates of Al-Jouf and Northern Borders regions.

Number of households belonging to both native and non-native persons per governorate had increased in all the regions during the period 2004-2010. We noticed a negligible decline in case of households of native persons in smaller governorates (Eastern Region and Tabouk) and in medium sized governorates (Al-Riyadh and Aseer). However, a noticeable decline was observed in smaller governorates of Jazan and larger governorates of $\mathrm{Al}$ Riyadh, Al-Qaseem and Aseer.

\section{Number of persons per household}

Number of households depends upon the number of persons in a governorate. Number of persons per household was 5.60 in the Kingdom, as of 2010; 6.45 in case of native persons and 4.08 in case of non-native persons, as compared to 5.48, 6.08 and 4.12, respectively, in 2004 (Table 6). The result suggests that the average household size was increased mainly among the native population, despite the effects of urbanization and modernization. No difference was observed across the various types of governorates on the number of persons per household, except in case of non-native persons. Larger governorates found to have bigger size households among nonnative persons, an indication of family status and housing issues, attached to labor VISA (provisions of family status and accommodation facilities). The situation improving with relaxed rules and regulations.

Number of persons per household in a governorate decreased during 2004-2010, especially in Makkah AlMokarramah, Al-Riyadh and Eastern Region, lowest increase was observed in Al-Baha, Jazan and Northern Borders.

\section{Coefficient of variation}

An attempt is made to extract variations in a few population dimensions of governorates grouped into three based on the number of native persons as shown in the Table 1. Indications of higher levels of variability within the governorates were observed. Variations decreased from 2004 to 2010 in case of all indicators for both small and medium sized governorates but the reverse is true in case of large governorates. Change in male ( -9.7 points) and female population of native ( 6.5 points) and thus the total native population $(-4.4$ points) indicates the differential growth of population at local geographic units that reflecting migrations more than other factors like natural increase (Table 7). On the other hand, the decrease in the coefficient of variation indicates a movement towards balance. It may also be due to redefinitions and 


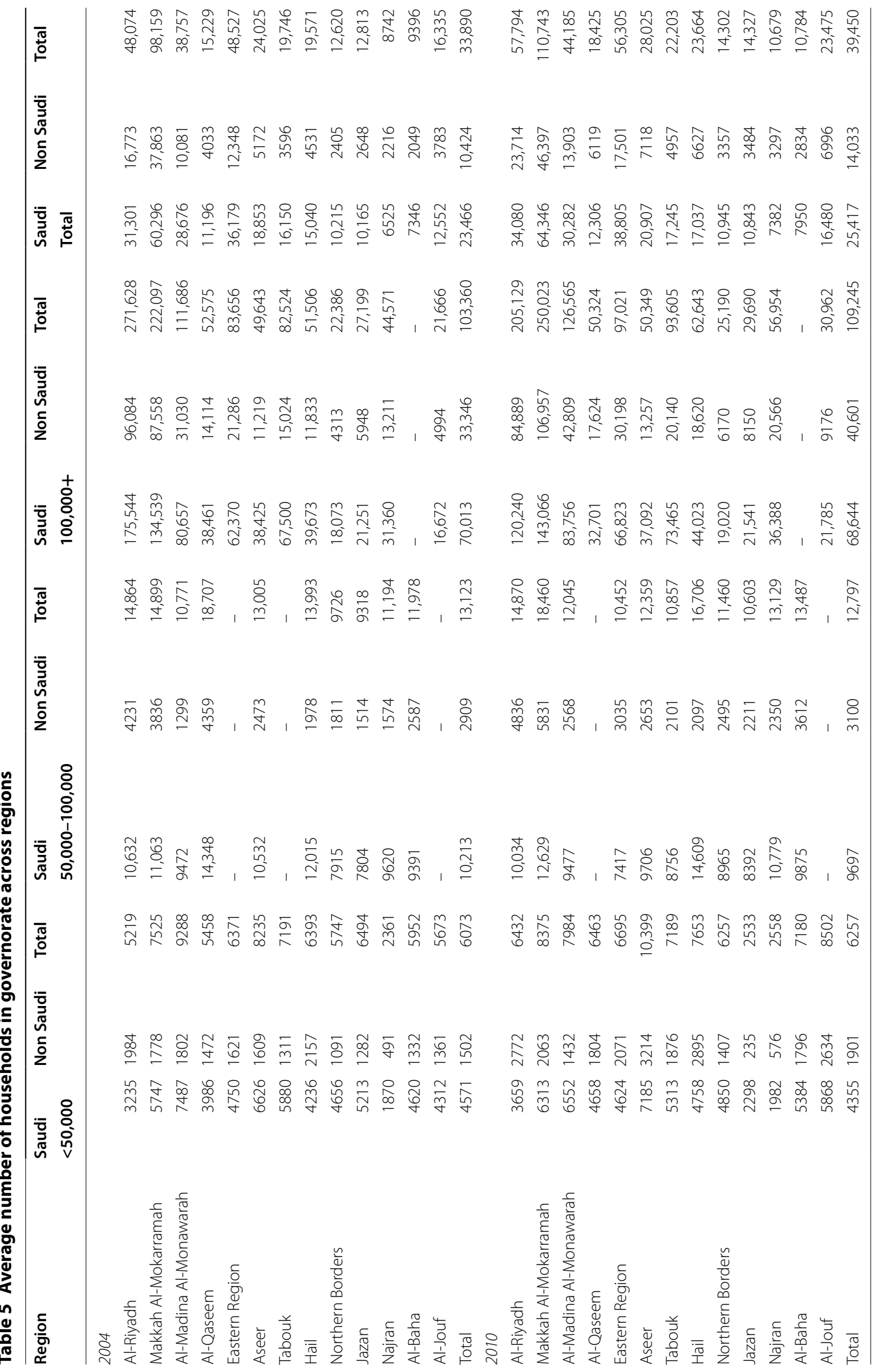




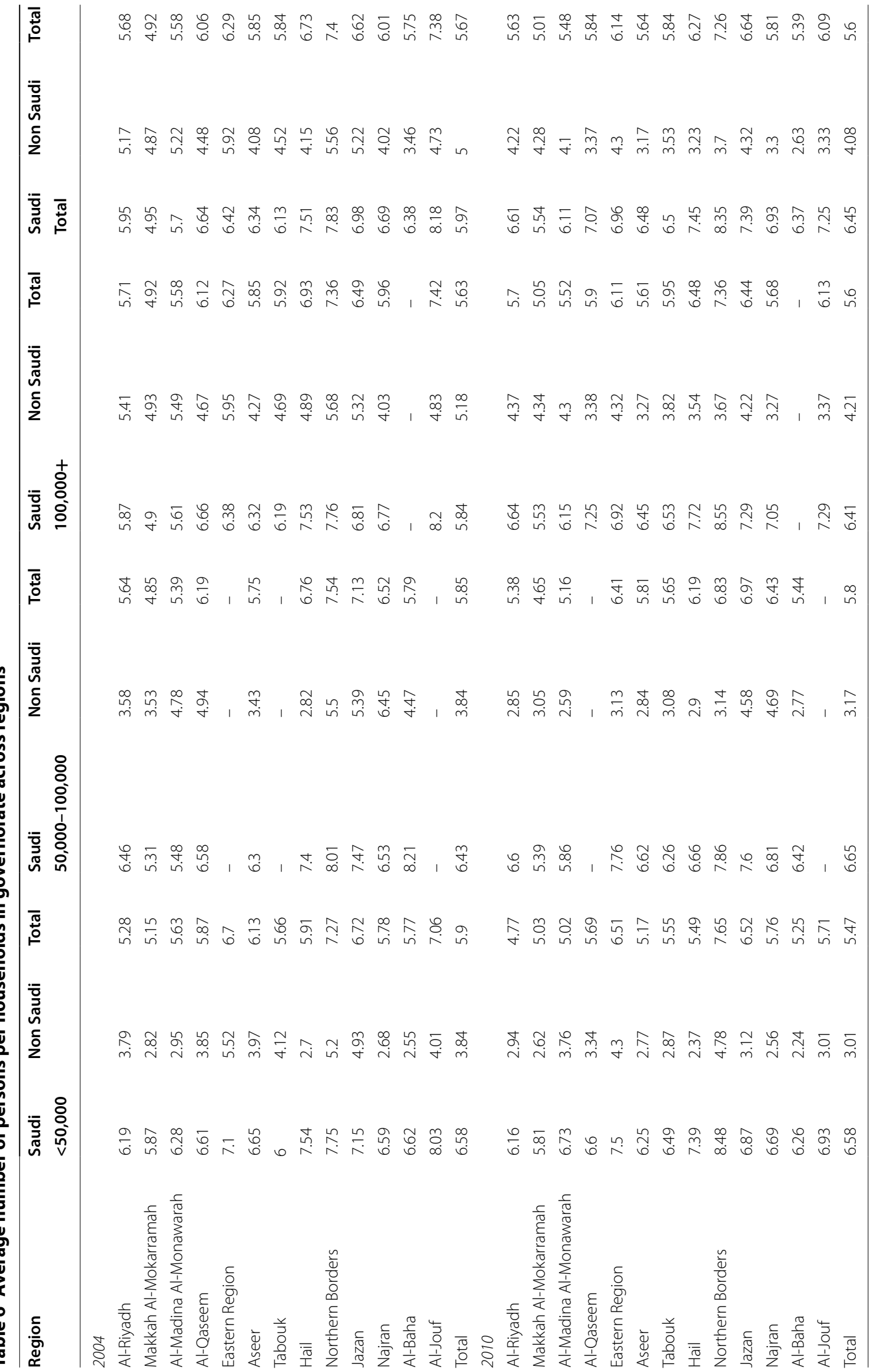




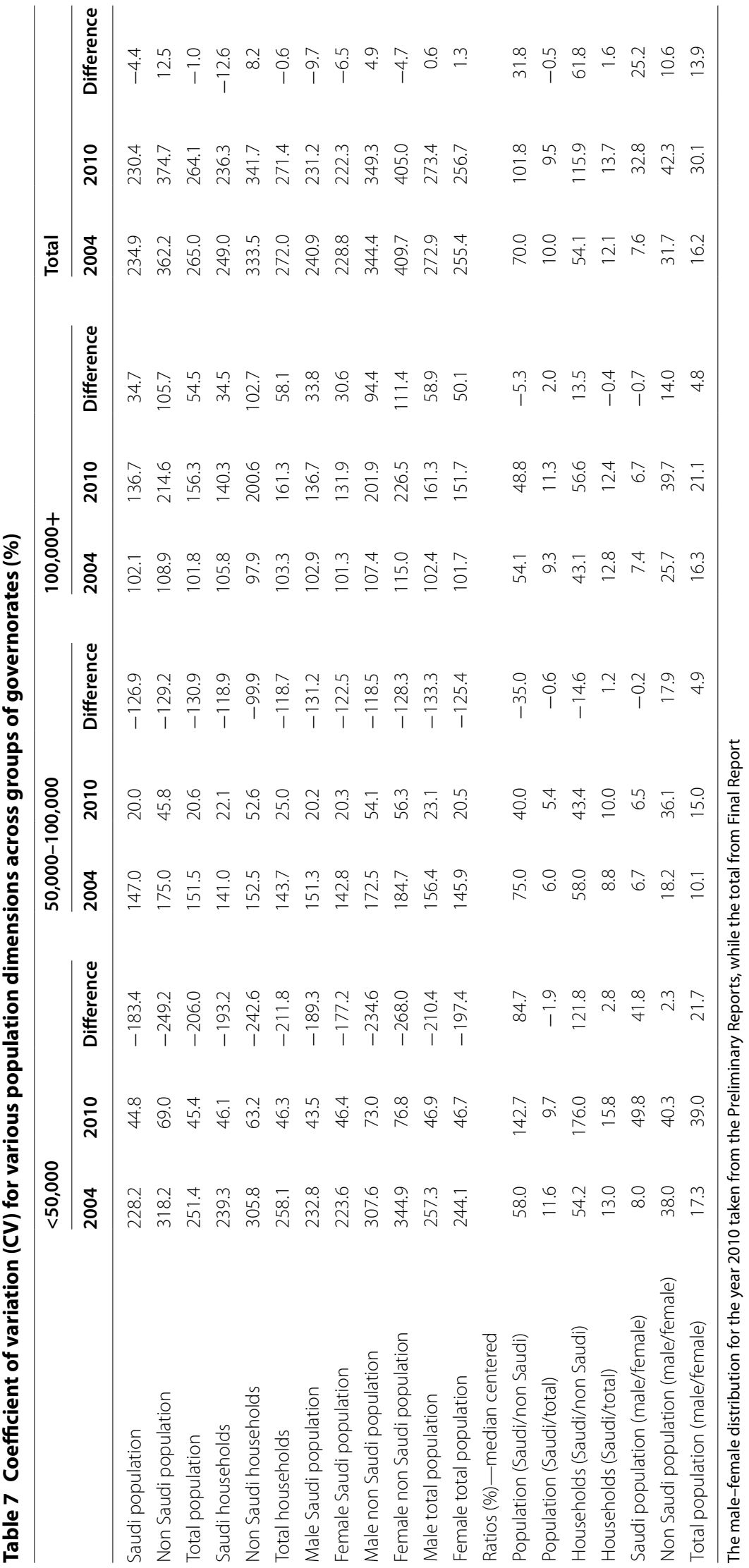


reclassification of governorates, during the intercensal period. The overall scenario is a mix of both increases and decreases. An increase of coefficient of variation noted in case of non-native population (12.5 points), non-native households (8.2 points), male non-native population (4.9 points), male total population (0.6 points) and female total population (1.3 points) indicating an unplanned and unexpected change in population, especially of nonnative (foreigners).

Small governorates have coefficients of variation increasing for all indicators except native population and female non-native population, indicating an increasing variability across governorates within the category: nonnative receiving greater attention for their increasing variability in terms of population, especially male. This reflects an imbalance of population size in the governorates and which is increasing. Imbalances remain larger in case of population and households of non-native. In the medium sized governorates, coefficient of variation decreased in 2010, except in case of non-naitve population (both male and female), indicating a movement towards balance. In the large governorates, the coefficient of variation was increased for all the indicators. The large governorates having urban agglomerations and increasing levels of infrastructure development pull people for occupational purposes leading to an increase in the residential population.

Median centered coefficient of variation of population shows good performance in the ratio of population native to total and of households. The balance of naitve male to female during 2004 (7.6) has lost during 2010 (32.8), reflecting a rapid change in population settlements probably due to rural to urban migration of males. A rapid imbalance observed in case of native to non-native population, indicating immigration trends and urbanization. A growing imbalance of sex is also noted.

\section{Conclusions and implications}

Population size of an administrative unit influences local level demographics - sex ratio, ratio of native to nonnative population, number of households and number of persons per household. Smaller administrative areas have a demographic profile different from that of larger areas, as seen from the data of Saudi Arabia. Population pressure increases developmental and infrastructural pressures, in turn, influencing the population characteristics. Larger governorates have more stable and developed administrative systems and structures, thus, having modern infrastructure and characteristics showing a balanced demography, in terms of sex ratio and persons per household. On the contrary, the medium sized units-the developing units-have accelerated growth of infrastructure requiring additional manpower, which is fulfilled through bringing people either from rural areas or from outside the country, thus altering population characteristics in line with masculinity, declining ratio of native to non-native population, changing household composition and thus persons per household. At the same time, small units usually are traditional, in terms of livelihoods and lifestyles that influences demographic structure and characteristics, but with exemption of qualifying as independent units.

The situation in Saudi Arabia follows a similar trend, but with the exceptions that the Kingdom has a huge share of foreign labor force; a majority of them lives in large administrative units. The exodus of foreign labor shows a diversion of demographic trends; high sex ratios, lesser proportion of native and smaller households. However, native population has characteristics close to the expectations-sex ratio close to 100 and has more than 6 persons per household.

Wide variations of administrative units in population size (male-female; native-non-native) and number of households, show an inequitable allocation caused due to the criterion set for qualifying an area to be recognized as an administrative unit. Reclassifications, in future, to equalizing units adopting a strict criterion (population size, geographic area combined with infrastructure development) shall balance this issue.

Changes happened from 2004 to 2010, on demographic characteristics of administrative areas reduce the gap, with exceptions in case of non-native population who constitutes the male dominated skewed adult labor force. The unprecedented increase in their numbers, despite the regulations in labor and immigration laws, during 20042010 , reduces the ratio of native to total population, especially in Makkah Al-Mokarramah, Al-Riyadh, the Eastern Region and Al-Madina Al-Monawarah regions.

This research made possible through analyzing national census carried out during 2004 and 2010 explored few basic demographics with the aim of exposing the Kingdom's grass root level planning and development as reflected in the local level demographic characteristics. Findings of this research have implications on both local level development plans as well as on improving or manipulating national demographic homogeneity. Developmental efforts are at a peak in the Kingdom even though with varying intensities across regions. While the East West Corridor (from Alkhobar to Jeddah governorate) develops faster, areas on the southern and northern side develop slowly, as shown by the data set, which may be addressed through population redistribution efforts with equitable developmental efforts. For the purpose, it is vital to improve the livelihoods and public infrastructure at poorly performing governorates, with an aim to integrate them into the main stream of the Kingdom so 
that people move to such localities for employment and residential purposes. Such efforts shall pave way for manipulating demographic characteristics like sex ratio, native-non-native ratio and persons per household-the three basic demographics discussed in this paper, which will raise the image of the Kingdom among the developed demographies of the world. It is also of importance to continue the collection of grass root level demographic data through Census and sample surveys at periodic intervals to create population based grass root level developmental plans, which will change the macro level indicators.

\section{Authors' contributions}

RK: overall advice, guidance. AAS: execution, data handling and analysis, interpretation of data. RS: review, revisions, improvisations, finalization. AA: monitoring the progress, review the drafts. IE: Support in analysis and interpretation of data. AM: support in analysis and interpretation of data. All authors read and approved the final manuscript.

\section{Author details}

${ }^{1}$ Center for Population Studies, King Saud University, Riyadh, Saudi Arabia.

${ }^{2}$ Karnataka Health Promotion Trust, Bangalore, India.

\section{Acknowledgements}

The authors would like to extend their sincere appreciation to the Deanship of Scientific Research at King Saud University, Riyadh for its funding of this research through the Research Group No. RGP-VPP-329.

\section{Competing interests}

The authors declare that they have no competing interests.

Received: 19 August 2015 Accepted: 23 August 2016

Published online: 30 August 2016

\section{References}

Al-Gabbani M (2008) Aging population in Saudi Arabia: changes and challenges. Paper presented at International Geographic Conference held in Tunis on 15 Aug

Alghamdi AM (1995) The housing cycle theory with regard to housing development in Saudi Arabia. J King Abdul Aziz Univ Eng Sci 7:59-67

Al-Khalifeh AH (1993) Population spatial distribution policies in Saudi Arabia. In: United Nations Economic and Social Commission for Western Asia (ed) Population spatial distribution. Amman ESCWA

Al-Mazrou YY, Farid SM, Khan MU (1995) Changing marriage age and consanguineous marriage in Saudi females. Ann Saudi Med 15(5):481-485

Al-Nasser AN, Bamgboye EA (1992) Estimates of fertility levels in a rural community of Saudi Arabia. Int J Fertil 37(1):15-18

Alrouh H, Ismail A, Cheema S (2013) Demographic and health indicators in Gulf Cooperation Council nations with an emphasis on Qatar. Local, Health Perspect 3

Babay ZA (2004) Trends of sex ratios in an urban Saudi Arabian population. Middle East Fertil Soc J 9(1):2004

Center for Population Studies (2012) Dynamics of Saudi Arabian population: analysis through four censuses-1974, 1992, 2004 and 2010. Center for Population Studies, Riyadh

Center for Population Studies (2013) Demography of Arab World: an assessment of three decades. Center for Population Studies, Riyadh

Collemore Y (2003) Saudi Arabia face population pressures. Population Reference Bureau, Washington

Courbage Y (1999) Economic and political issues of fertility transition in the Arab World - answers and open questions. J Interdiscip Stud 20(4):353-380
Freedman R (1995) Asia's recent fertility decline and prospects for future demographic change. Hawaii East West Center Program on Population, Honolulu

Jacobson J (1994) Family gender and population policy: views from the Middle East. The Population Council, New York

Khraif RM (1994) Residential mobility in the city of Riyadh: a study of its directions, reasons and characteristics. Occasional paper published by the Saudi Geographical Society. Riyadh. King Saud University

Khraif RM (2000) The labor force in Saudi Arabia: spatial dimensions and socioeconomic and demographic characteristics.Occasional papers referred published by Saudi Geographical Society. Riyadh King Saud University

Khraif RM (2007) Urbanization and growth of cities in Saudi Arabia. Kuwaiti Geographical Society, Kuwait

Khraif RM (2009) Fertility behaviors of grazing groups in Suman and Northern Parts of Saudi Arabia. Paper presented at XXVI IUSSP International Population Conference, Marrakesh Morocco 27 Sept-2 Oct

Makki M (1986) Regional and urban planning size weights in Saudi Arabia 1962-74. Geo J 13(2):111-118

Omran AR, Roudi-Fahimi (1993) The Middle East population puzzle. Popul Bull 48(1):1-40

Parasuraman S (2002) Global scenario of sex ratio: an overview. Presented at the symposium on sex ratio in India at IIPS, India Jan. 10-11

Rashad H (2000) Demographic transition in Arab countries: a new perspective. J Popul Res 17(1):83-101

Roudi-Fahimi N (1993) Population policies vary in Middle East. Popul Today 21(4):3-10

Samman ML (1985) Aspects of recent demographic trends in Arab countries of the Middle East. Espace Popul Soc 3:541-562

Shawky S (2001) Infant mortality in Arab countries: socio-demographic, perinatal and economic factors. Eastern Mediterr Health J 7(6):956-965

Sly DF, Serow WJ (1993) Population redistribution in the context of rapid population growth: the urbanization of the ESCWA region 1950-2000. In: United Nations Economic and Social Commission for Western Asia (ed) Population spatial distribution. Amman ESCWA

Susilawati C, Al-Surf M (2011) Challenges facing sustainable housing in Saudi Arabia: a current study showing the level of public awareness. In: 17th Pacific Rim Estate society conference. Gold Cost Australia, 16-19 January

Telvizian L (2009) The use of urban observatories as a tool for localizing urban and social policy. Economic and Social Commission for Western Asia, Beirut

UNDP (2004) Kingdom of Saudi Arabia_Human Development Report 2003. United Nations Development Program, Riyadh

United Nations (2002) The Arab Plan of Action on Ageing to the year 2012. Economic and Social Commission for Western Asia, Beirut

United Nations (2006) Country program document for Saudi Arabia (20072011). Executive board of the United Nations Development Program and of the United Nations Population Fund, New York

Wincker O (1997) The immigration policy of the Gulf Cooperation Council (GCC) states. Middle Eastern Stud 33(30):480-493

\section{Submit your manuscript to a SpringerOpen ${ }^{\circ}$ journal and benefit from:}

- Convenient online submission

- Rigorous peer review

- Immediate publication on acceptance

- Open access: articles freely available online

- High visibility within the field

- Retaining the copyright to your article

Submit your next manuscript at $\boldsymbol{\Delta}$ springeropen.com 